\title{
A escuta visual: a Educação de Surdos e a utilização de recurso visual imagético na prática pedagógica
}

Visual listening: Deaf education and the use of visual imagery in pedagogical practice

La escucha visual: la Educación de Sordos y la utilización de recurso visual imagético en la práctica pedagógica

* Patrícia Carla da Hora Correia

Professora doutora na Universidade do Estado da Bahia, Salvador, Bahia, Brasil.

patricia@inclusaodahora.com.br

\section{** Bárbara Coelho Neves}

Doutora da Universidade do Estado da Bahia, Salvador, Bahia, Brasil.

babi.coelho7@gmail.com

Recebido: 31 de maio de 2017

Aprovado: 13 de abril de 2018

\section{RESUMO}

O estudo que se apresenta neste artigo buscou responder a seguinte questão: Como o recurso pedagógico visual imagético influencia a práxis pedagógica dos professores, com enfoque na educação bilíngue, de educandos surdos do ensino Fundamental I de uma escola em Salvador-Bahia. A discussão se baseou nos aportes teóricos da Educação Bilíngue e Pedagogia Surda, abordando os seguintes autores: Lopes (2007), Oliveira (2009) Quadros, (2006), Reily (2003), Sánchez (1991, 2002), Skliar (1998), Strobel (2009) entre outros. A investigação foi de cunho qualitativo com base na Pesquisa-Ação e objetivou analisar o lugar que o recurso pedagógico visual imagético ocupa na práxis pedagógica dos professores, com enfoque na educação bilíngue de educandos Surdos do Ensino Fundamental I. O processo investigativo envolveu a reflexão individual, coletiva da prática pedagógica de três educadoras que atuam no Ensino Fundamental I, numa instituição voltada para a Educação de Surdos. Foram utilizados os seguintes recursos na coleta de dados: 1. Ficha (formulário de observação), 2- Utilização de filmagens (análise de vídeos) 3 - Entrevista semi-estruturada (elaborada pela pesquisadora). Os resultados evidenciaram, entre outros pontos, a experiência essencialmente visual da pessoa Surda requer uma reflexão sobre o efeito facilitador do material didático-pedagógico visual imagético utilizado, sua possível adequação e o uso de mídias como ferramenta didática, a fim de garantir-Ihes as condições linguísticas para a construção de sua subjetividade, desenvolvimento e inserção social.

Palavras-chave: Recurso pedagógico visual imagético; Educação bilíngue; Surdez. 


\section{ABSTRACT}

The study presented in this article sought to answer the following question: How the visual visual pedagogical resource influences the pedagogical praxis of teachers, with a focus on bilingual education, of deaf students of elementary school I of a school in Salvador-Bahia. The discussion was based on the theoretical contributions of Bilingual Education and Surda Pedagogy, addressing the following authors: Lopes (2007), Oliveira (2009) Quadros, (2006), Reily (2003), Sánchez, Strobel (2009) and others. The research was qualitative based on Action Research and aimed to analyze the place that visual visual pedagogical resource occupy in the pedagogical praxis of teachers, focusing on the bilingual education of Deaf students of elementary school I. The investigative process involved individual reflection, Collective of the pedagogical practice of three educators who work in Elementary School I, in an institution focused on the Education of the Deaf. The following resources were used in data collection: 1. Tab (observation form), 2- Use of filming (video analysis) 3 - Semistructured interview (elaborated by the researcher). The results evidenced, among other points, the essentially visual experience of the Deaf person requires a reflection on the facilitating effect of the didactic-visual visual material used, its possible adaptation and the use of media as a didactic tool, in order to guarantee the conditions Linguistics for the construction of their subjectivity, development and social insertion.

Keywords: Visual imaging resource; bilingual education; Deafness.

\section{RESUMEN}

El estudio que se presenta en este artículo buscó responder la siguiente pregunta: Como el recurso pedagógico visual imagético influye en la praxis pedagógica de los profesores, con enfoque en la educación bilingüe, de educandos sordos de la enseñanza Fundamental I de una escuela en Salvador-Bahía. La discusión se basó en los aportes teóricos de la Educación Bilingüe y Pedagogía Surda, abordando los siguientes autores: Lopes (2007), Oliveira (2009) Cuadros, (2006), Reily (2003), Sánchez (1991, 2002), Skliar (1998), Strobel (2009) entre otros. La investigación fue de cuño cualitativo con base en la InvestigaciónAcción y objetivó analizar el lugar que el recurso pedagógico visual imagético ocupa en la praxis pedagógica de los profesores, con enfoque en la educación bilingüe de educandos Sordos de la Enseñanza Fundamental I. El proceso investigativo envolvió la reflexión individual, colectiva de la práctica pedagógica de tres educadoras que actúan en la Enseñanza Fundamental I, en una institución orientada a la Educación de Sordos. Se utilizaron los siguientes recursos en la recolección de datos: 1. Ficha (formulario de observación), 2- Utilización de filmaciones (análisis de vídeos) 3 - Entrevista semiestructurada (elaborada por la investigadora). Los resultados evidenciaron, entre otros puntos, la experiencia esencialmente visual de la persona surda requiere una reflexión sobre el efecto facilitador del material didáctico-pedagógico visual imagético utilizado, su posible adecuación y el uso de medios como herramienta didáctica, a fin de garantizarles las condiciones lingüísticas para la construcción de su subjetividad, desarrollo e inserción social.

Palabras clave: Recurso pedagógico visual imagético; Educación bilingüe; Sordera. 
Introdução

DOI: $10.5902 / 1984686 \times 27435$

Nas últimas décadas variadas mudanças vem ocorrendo em diversos campos da sociedade. São mudanças globalizadas e que afetam o continente latino-americano. Fenômenos que geram um número significativo de crianças, jovens e adultos expostos às situações de risco o que influencia, sobretudo, no âmbito educacional. Por isso, enquanto espaço de produção do conhecimento cabe à escola a repensar a nossa sociedade e possibilitar a construção efetiva de recursos e estímulos cognitivos, visando potencializar a produção de melhores respostas às questões sociais enfrentadas nos espaços educacionais.

A discussão que se propõe conduz a possibilidade de se repensar a importância da utilização do recurso pedagógico imagético, para que alunos surdos sejam convidados para o debate, ou seja, tornarem-se sujeitos partícipes das atividades pedagógicas propostas na medida em que o elemento visual, contribua para o reconhecimento daqueles como sujeitos e como cidadãos, podendo se apropriar de informações, transformá-las em conhecimento, em saber e assim se empoderarem do lugar de sujeitos pensantes capazes de emitir a sua voz.

As constantes mudanças nos setores econômico e social e o progresso da cibernética e das tecnologias de informação têm sido as marcas da Pós Modernidade. É surpreendente como as crianças utilizam a tecnologia, Larrosa, diz que: "[...] teremos que aprender a viver de outro modo, a pensar de outro modo, a falar de outro modo, a ensinar de outro modo". Esta citação contribui para que o educador analise a sua postura frente às novas metodologias de ensino que são colocadas na sua formação como oportunidades de inserção das tecnologias ao fazer pedagógico, como uma nova concepção de ensino se contrapondo aos modelos postos pela sociedade até então.

No entanto, é necessário considerar que as mudanças vêm ocorrendo rapidamente, e nem sempre são priorizadas as tradições em diferentes grupos sociais. Mais uma vez, é a cultura do povo que é descaracterizada e desqualificada frente à tão ostentada, cultura global. De acordo com a Lei de Diretrizes e Bases da Educação Nacional, Lei 9394/96 a educação é direito de todos os cidadãos brasileiros, Surdos ou não, e cabe aos sistemas de ensino garantir as condições que avalizem o acesso ao currículo e à informação.

\section{Método e material de pesquisa}


DOI: $10.5902 / 1984686 \times 27435$

A trajetória formativa e a atuação profissional em uma escola especializada influenciaram os caminhos desta pesquisa. Percebendo-se o nível de complexidade em que se estrutura este fazer pedagógico e os reflexos do Surdo na sala de aula, surgiu a seguinte pergunta: como o recurso pedagógico visual imagético influencia a práxis pedagógica dos professores, com enfoque na educação bilíngue, de educandos surdos do Ensino Fundamental I de uma escola em Salvador?

Sabe-se que a inadequação dos recursos didáticos agrava o processo educativo do surdo. Essa pesquisa teve como objetivo geral: analisar o lugar que o recurso pedagógico visual imagético ocupa na práxis pedagógica dos docentes, com enfoque na educação bilíngue de educandos Surdos do Ensino Fundamental I. Os objetivos específicos que essa pesquisa se propôs descortinar: identificar em que momento as representações visuais, como estratégia de ensino, são utilizadas pelos docentes durante sua práxis; investigar a importância que os docentes não Surdos atribuem ao recurso imagético em sua sala de aula com educando surdo; e descrever os posicionamentos reflexivos na prática educativa bilíngue do docente, após aplicação de um workshop com recursos imagéticos.

O trabalho foi realizado através de uma pesquisa-ação com base na formação reflexiva do trabalho pedagógico investigando, produzindo conhecimentos sobre a realidade a ser estudada e realizando concomitantemente um processo educativo para 0 enfrentamento dessa mesma realidade. Thiollent (2007) define a pesquisa-ação como sendo:

[...] um tipo de pesquisa social com base empírica que é concebida e realizada em estreita associação com uma ação ou com a resolução de um problema coletivo e no qual os pesquisadores e os participantes representativos da situação ou do problema estão envolvidos de modo cooperativo ou participativo. (THIOLLENT, 2007, p. 16)

Outro ponto destacado por este autor que justifica a escolha pela pesquisa-ação está vinculado aos objetivos, pois nesta abordagem metodológica estão presentes tanto os objetivos práticos como os de conhecimento, podendo existir uma concentração maior no primeiro ou no segundo, a depender do foco da investigação. Neste caso, co-existem os dois tipos de objetivos, sendo que os de conhecimento se sobrepõem, visto que as questões que envolvem o processo de ensino-aprendizagem da educação do sujeito Surdo 
DOI: $10.5902 / 1984686 \times 27435$

são problemáticas não só para os professores dessa escola em Salvador, como também são temas de interesse para os demais profissionais que atuam com esses educandos.

Após reconhecimento do problema realizou-se filmagem de aulas de três professores dessa escola, em uma instituição pública especializada no trabalho com crianças surdas. Aplicou-se questionário com o objetivo de caracterizar estes profissionais, de colher informações sobre produção e uso do recurso didático adequado e entrevista.

As filmagens como principal material de análise para levantamento de dados da presente pesquisa tiveram sessões reflexivas das aulas das docentes. Tomando como referência a questão norteadora deste estudo, foi necessário organizar as oficinas individualmente e teve uma proposta aberta, onde as professoras assistiram às aulas filmadas e sugeriram os momentos de análise dos posicionamentos reflexivos sobre a docência com Surdo, com o levantamento de pontos e questões importantes, com o objetivo de editar o DVD. Feito isso, foi implementada a segunda parte da pesquisa com uma oficina, tipo Workshop, elaborada com o propósito de discutir especificamente o uso dos recursos didáticos pedagógicos imagéticos visuais pelo professor como fator mobilizador/mediador de aprendizagem do educando Surdo do Ensino Fundamental.

A fim de traçar o perfil e o percurso profissional do grupo de docentes na atuação com surdos, utilizou-se mais dois recursos: o primeiro constou em um formulário contendo questões sobre a formação inicial e continuada das profissionais e o tempo com a Educação de Surdos; o outro recurso foi à entrevista individual para esclarecer a sua inserção na docência com estes sujeitos, abordando a sua prática pedagógica, identificando os caminhos percorridos e as dificuldades encontradas. Na entrevista, foi adotado um formato semi-estruturado, que de acordo do Minayo (2007, p.64) são “[...] entrevistas que combinam perguntas fechadas e abertas, onde o entrevistado tem a possibilidade de discorrer sobre o tema proposto, sem respostas ou condições prefixadas pelo pesquisador". Constituíramse como principais participantes deste estudo o segmento professor. Os sujeitos da pesquisa foram um total de 3 docentes do sexo feminino ouvintes que atuavam em turmas variadas com níveis de ensino diferentes - Ensino Fundamental I ( $2^{\circ}$, $3^{\circ}$ e $4^{\circ}$ ano). O processo para a seleção se deu a partir do interesse das docentes em colaborar com o estudo e que atuassem no Ensino Fundamental. Apresentou-se o projeto durante uma reunião de Atividade Complementar $(\mathrm{AC})$ que acontece semanalmente às quartas-feiras. 


\section{DOI: $10.5902 / 1984686 \times 27435$}

De acordo com os objetivos pretendidos, este texto teve como base teórica, autores que realizam estudos consistentes no que diz respeito à Educação de Surdo, tais como: Lopes (2007) Oliveira (2009), Ronice, (2006), Sánchez (1991, 2002), Skliar (1998), Strobel (2009), Reily (2003), entre outros.

\section{Lugares epistemológicos}

No Brasil, em 1857, a educação de Surdos foi marcada com a vinda do professor francês Eduard Huet, convidado pelo imperador D. Pedro II para desenvolver um trabalho pedagógico com estes educandos. A sua atuação foi iniciada com duas crianças surdas (GOLDFELD, 2002), neste período, no dia 26 de setembro, foi fundada a primeira escola para surdos no Rio de Janeiro, o Instituto Nacional de Surdos-Mudos onde a educação com este grupo foi institucionalizada.

A docência com surdos possui uma especificidade, pois os mesmos vão ao encontro da 'Outridade'. Sendo assim os docentes que trabalham com Surdos, utilizam a imagem como um recurso pedagógico interessante para estimular a curiosidade destes educandos. Skliar (1997 p. 126-127) afirma que:

[...] se os surdos foram excluídos de aprendizagens significativas, obrigados a uma prática de atividades sensório-motoras e perceptuais, mas não de conteúdo de abstração, se foram impedidos de utilizar a Língua de Sinais em todos os contextos de sua vida, então nada têm a ver os surdos nem a Língua de Sinais com as supostas limitações no uso dessa língua, na aquisição de conhecimentos e no desenvolvimento de seu pensamento (SKLIAR, 1997, p.126-127).

Corroborando com esse pensamento é que se entende, entre outros aspectos, a importância de encorajar práticas imagéticas que promovam situações interativas e que possam agregar valores e condições sociais para futuras aprendizagens, dada a crescente disseminação de usos das tecnologias digitais na área educacional.

Neste contexto, em oposição a oralidade surge a comunicação total. A nova abordagem pedagógica surgiu como filosofia e não como método. Adotou-se todas as formas de comunicação, objetivando a aquisição da língua majoritária, que, no caso do Brasil, é o Português. Conforme afirma (GOLDFELD, 2002),

A filosofia da Comunicação Total tem como principal preocupação os processos comunicativos entre surdos e surdos e entre surdos e ouvintes. Esta Filosofia também se preocupa com a aprendizagem da língua oral pela criança surda, mas acredita que os aspectos cognitivos, emocionais e sociais não devem ser deixados de lado em prol do aprendizado exclusivo da língua 


\section{DOI: $10.5902 / 1984686 \times 27435$}

oral. Por esse motivo [...] defende a utilização de recursos espaços-visuais como facilitadores da comunicação (GOLDFELD, 2002, p.38).

Assim, os recursos didáticos podem contribuir como agentes de acessibilidade ao conhecimento, e como tais, proporcionam aos alunos o conviver, o trocar, o construir-se. $\mathrm{Na}$ troca de experiências com o outro, ele influencia e é influenciado, tem a capacidade de julgar e extrair suas próprias conclusões, equilibrando assim seus esquemas mentais e suas emoções.

Talvez, em nenhuma outra forma de educação os recursos didáticos assumam tanta importância como na Educação Especial na perspectiva da Educação Inclusiva. O recurso didático imagético tem se revelado como um importante campo a ser explorado, muitos mais que o mero uso de uma ferramenta de trabalho sofisticada.

Reily (2003) chama atenção para a importância da imagem no currículo de crianças surdas, atentando para a necessidade do letramento visual nas escolas, sugerindo que os educadores precisam fazer uma maior reflexão sobre o papel da imagem visual na produção do conhecimento. Salienta a necessidade de utilizar-se a imagem adequadamente como recurso cultural que permeia todos os campos de conhecimento e que traz consigo uma estrutura capaz de instrumentalizar o pensamento.

Logo, o letramento visual (REILY, 2003) é uma área que precisa ser melhor aproveitada pelos profissionais da surdez. Devem ser incentivadas na escola as leituras de imagens e estratégias visuais de leitura e interpretação e o uso dos recursos tecnológicos terá uma significativa contribuição. O profissional da área precisa experimentar na sua práxis como é possível utilizar os recursos visuais imagéticos para melhor compreender um texto. As imagens podem ser lidas e interpretadas, portanto qualquer conteúdo pode ser organizado a partir de informações visuais.

Segundo Sánchez (1991, p.4), o conceito de educação bilíngue, na área da surdez, significa:

\footnotetext{
Reconhecer que a língua de sinais dos surdos é uma língua natural, criada e utilizada por um grupo humano para comunicar-se e para construir seu conhecimento de mundo e que, por conseguinte, os surdos constituem uma comunidade linguística minoritária.
}

Corroborando com Simões, Zava, Silva e Kelman (2011, p.3609) enfatizam que "[...] o ensino de alunos surdos apoia-se em duas vertentes, o bilinguismo e o uso de recursos 


\section{DOI: $10.5902 / 1984686 \times 27435$}

especiais, baseados na experiência visual". Nessa mesma direção, Campello (2007) enfatiza a importância da imagem:

[...] exploração de várias nuances, ricas e inexploradas, da imagem, signo, significado e semiótica visual na prática educacional cotidiana, procurando oferecer subsídios para melhorar e ampliar o leque dos "olhares" aos sujeitos surdos e sua capacidade de captar e compreender o "saber" e a "abstração" do pensamento imagético dos surdos. (CAMPELLO, 2007, p. 130)

Lacerda Santos e Caetano (2011) abordam sobre a importância dos recursos visuais na prática pedagógica docente e afirmam que:

[...] a escola pode colaborar para a exploração das várias nuances da imagem, signo, significado e semiótica visual na prática educacional cotidiana, oferecendo subsídios para ampliar os "olhares" aos sujeitos Surdos e à sua capacidade de captar e compreender o "saber" e a "abstração" do pensamento imagético. (LACERDA; SANTOS; CAETANO, 2011, p. 108)

As representações visuais como estratégia metodológicas para o educando surdo, é muito importante considerando o lugar em que os sujeitos ocupam no acolhimento às suas diferenças. Os surdos são essencialmente visuais, portanto, a imagem é recurso essencial para que possam se apropriar das informações presentes no seu contexto cultural, social, político, linguístico e ideológico.

De acordo com Silva (2001 p. 20):

[...] a inclusão do aluno surdo não deve ser norteada pela igualdade em relação ao aluno ouvinte e sim por suas diferenças sócio-histórico-cultural, às quais o ensino se sustente em fundamentos lingüísticos, pedagógicos, políticos, históricos, implícitos nas novas definições e representações sobre a surdez [...]. Portanto, que se tenha um currículo em LIBRAS e uma pedagogia centrada no ensino da escrita, no caso do aluno brasileiro, o português.

O valor pedagógico atribuído pelos docentes não surdos, ao recurso visual imagético é um ponto estruturante em que esta pesquisa encontra-se apoiada. Compreender a importância e o lugar que o recurso visual imagético ocupa na práxis pedagógica, numa perspectiva de uma educação bilíngue de um docente ouvinte, é o objetivo principal a que essa pesquisa se propõe.

Uma reflexão sobre a prática educativa bilíngue do docente ouvinte, a partir da utilização dos recursos visuais imagéticos, apresenta-se pertinente para a aprendizagem do educando surdo. Pensar sobre o seu fazer pedagógico apresentando na sua prática o sentido e significado do texto imagético, dota a representatividade do olhar do docente 
DOI: $10.5902 / 1984686 \times 27435$

frente ao ensinante', surdo. Isto faz com que o docente recorra à imagem como chamamento para o surdo fazer parte do discurso e assim a aprendizagem se estabeleça.

\section{Recurso pedagógico visual imagético: potencial para novas adequações metodológicas}

As imagens têm sido o veículo de expressão e comunicação humana desde a préhistória. E como forma de comunicação adquiriu dimensões extraordinárias, tanto que permeia a vida cotidiana com mensagens visuais que norteiam a organização da atividade humana em sociedade. Para o sujeito surdo é necessário educar o olhar para que seja desenvolvida a percepção visual. Para Strobel (2009), o sujeito surdo encontra o mundo com os olhos e, essa experiência visual, favorece a comunicação com o meio. Em relação e esse fato Skliar enfatiza,

[...] a surdez é uma experiência visual [...] e isso significa que todos os mecanismos de processamento da informação, e todas as formas de compreender o universo em seu entorno, se constroem como experiência visual. Não é possível aceitar, de forma alguma, o visual da língua de sinais e disciplinar a mente e o corpo das crianças surdas como sujeitos que vivem uma experiência auditiva. (SKLIAR, 2013, p. 28).

A língua de sinais para a comunidade surda exerce justamente o papel de propiciadora de inserção cultural, pois, é através dela que o indivíduo Surdo passa ter contato com seus pares, com sua cultura o que favorece diretamente 0 desenvolvimento de sua identidade. É através da língua de sinais que os Surdos têm a garantia de acesso aos saberes científicos construído em nossas escolas. Segundo Vygotsky (1999) os conceitos são construções culturais, que vão sendo internalizadas pelo indivíduo no decorrer do processo de desenvolvimento.

No entanto, no que diz respeito ao processo de aquisição de conceitos por sujeitos surdos, destaca-se que além da oferta de educação em sua primeira língua, garantida sob força do decreto nº 5.626 (BRASIL, 2005), a utilização de recursos visuais como suporte para tal aquisição, atualmente nomeada pedagogia visual Buzar (2009), tem se apresentado como uma prática pedagógica que visa à garantia da aprendizagem significativa para essa parcela da sociedade. Kelman (2011) nos remete ao fato de que além da utilização da linguagem oral e da língua de sinais nos processos de ensino/aprendizagem, a utilização de recursos visuais variados pode contribuir significativamente para a aprendizagem de crianças Surdas, salientando a necessidade de 


\section{DOI: $10.5902 / 1984686 \times 27435$}

que esses recursos estejam inseridos nas estratégias pedagógicas direcionadas aos educandos.

A utilização por educadores do recurso didático visual imagético, tornou-se um instrumento comum para o ensino, mas traz diferentes graus de complexidade garantindo a aprendizagem do aluno. Os surdos conhecem o mundo pela visão e isso significa desenvolver um código visual, ou seja, associar significado e significante a partir das informações visuais que extraem do meio.

Por meio do recurso didático adequado os educandos se identificam e desenvolvem autoestima, imaginação, confiança, controle, criatividade, cooperação, senso de percepção e o relacionamento interpessoal, desta forma, evidencia-se, que uma das características fundamentais do recurso didático adequado é funcionar como veículo estimulador do desenvolvimento humano, agindo de forma global e integrada nesse processo.

A utilização de imagens no seu processo de aprendizagem justifica-se pela marca constitutiva da identidade. Para ilustrar esta forma diferente de estar e perceber o mundo apresento a concepção de Strobel (2008), uma pesquisadora surda:

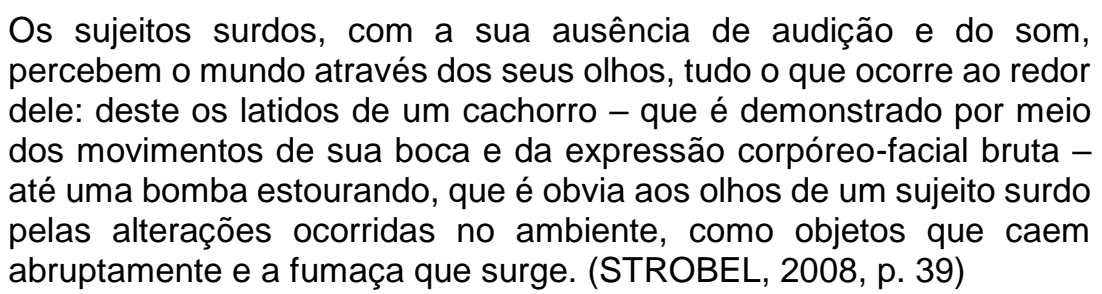

Reily (2003, p. 164) propõe o letramento visual no currículo escolar e considera que a "imagem vem sendo utilizada na escola com uma função primordialmente decorativa, de tal forma a diluir o tédio provocado pela grafia de textos visualmente desinteressantes". Dada à característica visual da língua de sinais, essa discussão deve se fazer presente no campo da surdez; nesse sentido, Reily também enfatiza a importância de educadores da área refletirem sobre o papel da imagem no processo de escolarização de surdos.

A experiência visual do surdo apresenta-se como elemento preponderante para o seu aprendizado, neste sentido os docentes devem se apropriar dessa ferramenta pedagógica. Os conceitos dos docentes precisam ser repensados quanto ao que se ensinar e aprender, sendo necessário construir novos sentidos em relação a concepção de quem é o surdo e a sua visão de mundo. Daí a importância da adequação do recurso pedagógico visual imagético como potencial da aprendizagem dos educandos surdos. 
DOI: $10.5902 / 1984686 \times 27435$

\section{Aspectos percebidos em pesquisa com surdos na utilização de recursos imagéticos em ambiente escolar}

Ao se discutir os pontos principais observados durante as aulas e após assistir as filmagens, percebe-se que, apesar de cursos na área da surdez, as incorporações de estratégias visuais pelo docente ainda são muito tímidas na sistematização de seu uso para fins pedagógicos no currículo. Concluídas as apreciações, solicitou-se às professoras que compuseram a amostra deste estudo, que assistissem à filmagem, selecionasse os trechos mais relevantes e fizessem comentários a respeito da aula ministrada, fazendo referência ao recurso didático utilizado. Para realizar possível interrelação entre os dados e preservar a identidade das docentes participantes da pesquisa, atribuiu-se um codinome que teve a letra inicial do seguimento. Assim as docentes foram identificadas com nomes que iniciaram com a letra "P", formando o grupo da seguinte forma: Pollyanna e Pâmela. A opção por nomes fictícios, em detrimento do uso de códigos (letra e números), deve-se ao fato de acreditar que essa forma de identificação possibilita melhor tratamento dos dados.

[...] - Acho que o material que utilizei foi muito pobre, apesar de ter feito desenhos no quadro, estimulando o visual do aluno, precisaria de um recurso mais apropriado para trabalhar o conteúdo Higiene Bucal. O maior problema é que o tempo é curto para planejar e diversificar as atividades e a pouca habilidade com as TIC. (POLLYANNA).

[...] - Eu gosto muito de utilizar o desenho, mas, acredito que ficaria muito melhor para o aluno surdo o uso de imagens coloridas e uso das novas tecnologias, fazendo PowerPoint, utilizando o monitor educacional, usando o datashow. Só que para isso a escola não ajuda... Espero que você contribua com a gente. (PÂMELA).

Nas falas das docentes percebe-se que elas reconhecem e compreendem que necessitariam de estratégias e metodologias novas para melhorar suas práticas pedagógicas, adequá-las, criar situações de aprendizagens reais no intuito de ampliar as possibilidades do educando Surdo, tendo em vista o reconhecimento da diferença essencialmente visual e, assim, possam construir novos conhecimentos e a aprendizagem de fato aconteça.

Considera-se o momento de análise, reflexão e discussão muito enriquecedor, pois, as docentes estavam diante de sua prática pedagógica, podendo sugerir, modificar e adequar materiais que seriam utilizados nas próximas aulas. Constatou-se nas falas das educadoras a necessidade do uso da imagem e do material adequado às especificidades 


\section{DOI: $10.5902 / 1984686 \times 27435$}

do educando Surdo, como forma de garantir que o conteúdo curricular seja oferecido sem perda de qualidade do ensino-aprendizagem.

O uso do recurso pedagógico visual imagético, no processo de aprendizagem da pessoa surda é marca constitutiva desse sujeito e é definida pela experiência visual. Não nos comunicamos apenas por meio da fala ou de sinais, mas também por recursos visuais variados (KELMAN, 2011). Assim, as crianças surdas aprendem melhor quando recursos visuais são incluídos nas estratégias pedagógicas utilizadas.

Figura 1 - Material da aula (professora Pollyanna), antes do Workshop

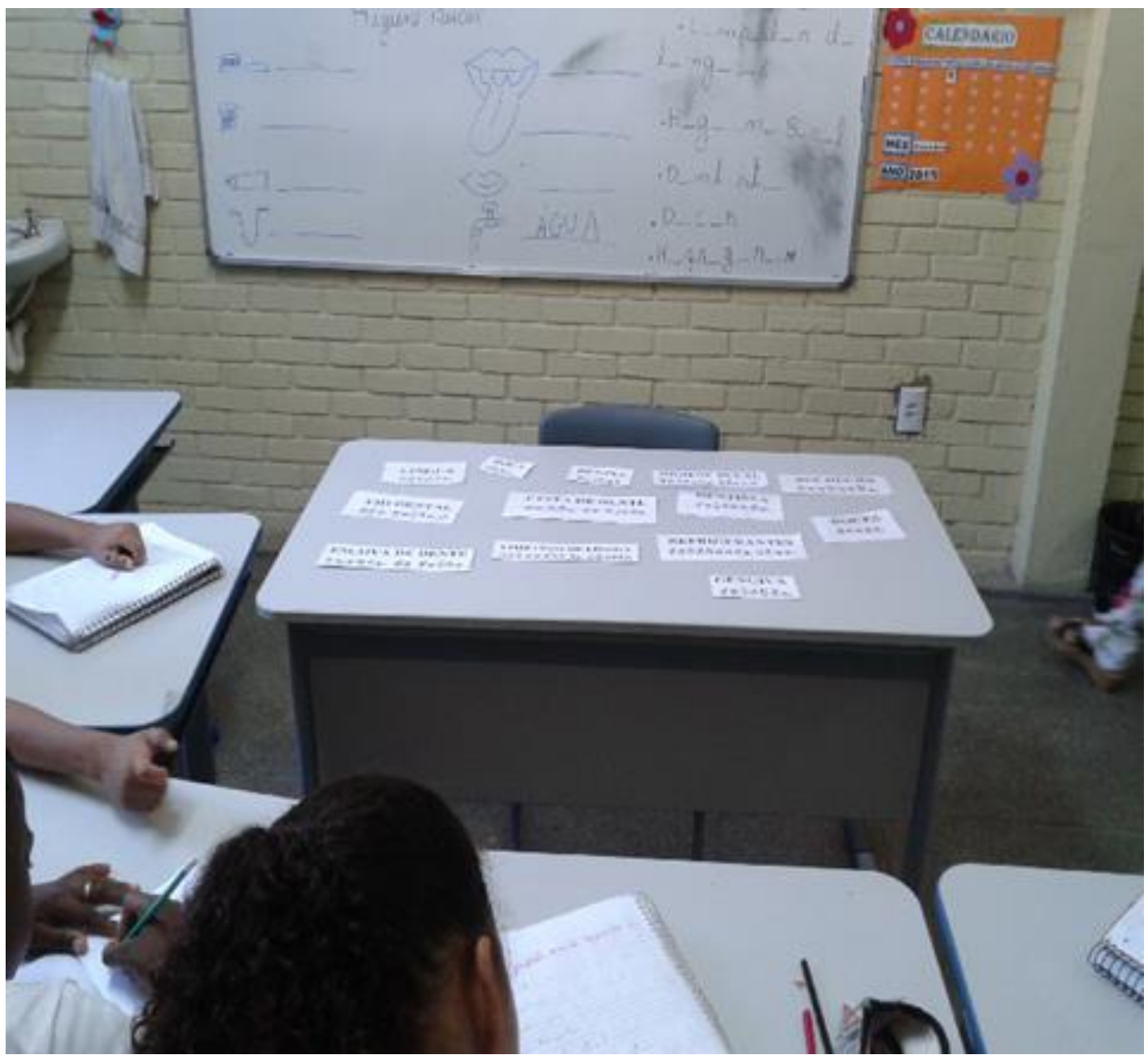

Fonte: Dados da Pesquisa (2016).

Organizar este espaço sociopedagógico serve de ponte para que a imagem seja compartilhada de maneira horizontalizada reconhecendo a diferença identitária e cultural destes sujeitos surdos. Utilizar caminhos visuoespaciais para a aprendizagem dos alunos surdos é extremamente importante tendo em vista a singularidade destes, por serem 


\section{DOI: $10.5902 / 1984686 \times 27435$}

pessoas visuais. Como pode-se perceber na imagem posta (Fig. 1), a professora percorreu vários caminhos para que o seu objetivo da aprendizagem fosse alcançado.

O caminho seguido posteriormente foi a realização de um workshop com a seguinte metodologia: apresentação do material ao grupo, análise, discussão, confecção e sugestão do recurso adequado à aula de cada docente. Buscando a compreensão dos relatos referentes aos procedimentos pedagógicos, apresenta-se a seguir o material da aula ministrada pela professora Pollyanna, para desenvolver o conteúdo "Higiene Bucal" considerando as características de recursos visuais necessárias ao sujeito Surdo.

O texto imagético referendado nesta fotografia (Fig. 2) legitima a pluralidade de caminhos pedagógicos, escrita no quadro, desenhos, fichas, explicações individuais, tudo a partir do enfoque visual. Constatou-se, portanto na imagem um recurso preponderante para que a aprendizagem de fato se constitua. Escreve no quadro, desenha, usa fichas e quando necessário, promove explicações individuais a partir do enfoque visual. Por exemplo: fazer desenhos ao lado de cada palavra.

Embora existisse pouca experiência dos docentes com o uso das tecnologias, foram congregadas atividades ao workshop, visando desenvolver uma atitude colaborativa. Essas atividades colaborativas vivenciadas pelo grupo foram permeadas de atitudes potencializadoras do trabalho participativo explicitadas por Almeida e Prado (2003), como abertura, humildade, compartilhamento, respeito, acolhimento ao outro, cumplicidade, compromisso com a equipe e com o trabalho em si e a partir da mediação na pesquisa. Foram realizadas pesquisas on-line para confecção materiais imagéticos a serem utilizados nas aulas. Foi distribuído também um kit com o material produzido pelas participantes e um manual com instruções. Refletindo sobre o objetivo, metodologia e avaliação do recurso pedagógico utilizado.

A partir das reflexões, o grupo pôde perceber que os sujeitos surdos possuem processos distintos de aprendizagem. $O$ texto imagético não deve ser observado somente como um modo de preencher a explicação e a atividade. A imagem deve ser o deflagrador da explicação, fazer parte do conteúdo e sugerir ao educando uma reflexão crítica. 
Figura 2 - Realização do Workshop com os sujeitos da Pesquisa
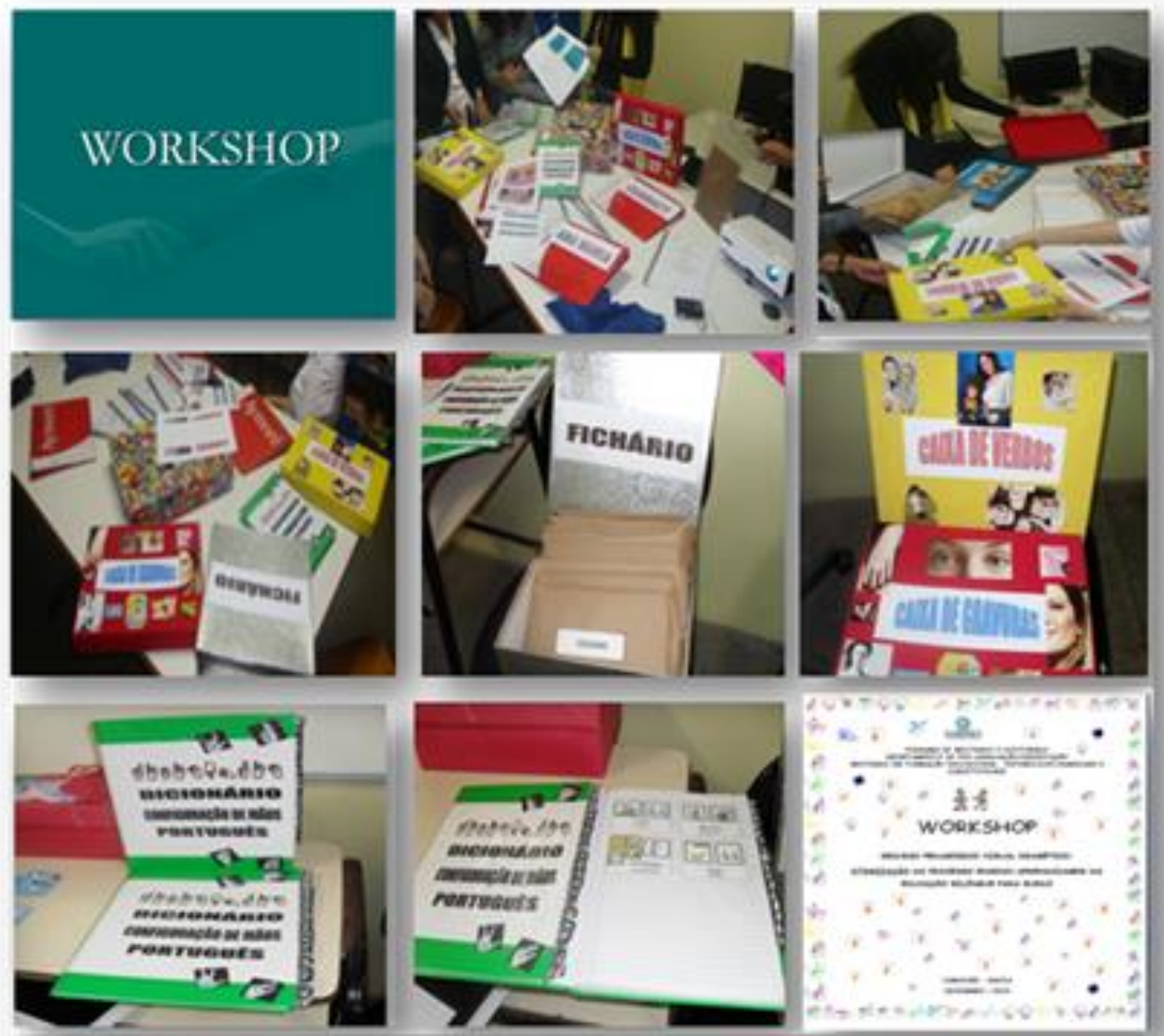

Fonte: Dados da pesquisa (2017).

O contato com imagens sensibiliza e educa o olhar. Por isso, essa prática no contexto escolar e na educação do surdo deve ser explorada em um diálogo de imagem e leitor, oferecendo uma visão integral e simultânea de um tema e ainda possibilitando outras maneiras de compreendê-lo. Além disso, elas convocaram os alunos a estabelecerem contato visual, fator imprescindível na constituição de significados pelos educandos surdos gerando debates, reflexões e discussões sobre o assunto, contando com a participação espontânea de todos os educandos da sala de aula. 
DOI: $10.5902 / 1984686 \times 27435$

Os educandos foram, paulatinamente, acompanhando suas explanações sem grandes dificuldades. Alguns acompanhavam as explicações e vibravam com seu aprendizado, tentavam criar mecanismos individuais e coletivos que dessem respostas aos desafios que as docentes iam disponibilizando através de vários questionamentos. Verificou-se que a mediação do conteúdo para os educandos surdos foi realizada por meio da Libras, pelas docentes. Outro aspecto relevante observado nas aulas, foi o fato de que os recursos visuais foram apresentados em forma de PowerPoint, material imagético, auxiliando a memorização gráfica das mesmas, que apenas terão significado se forem contextualizadas.

Figura 3 - PowerPoint do material da aula ministrada pela professora (Pollyanna) após realização do Workshop

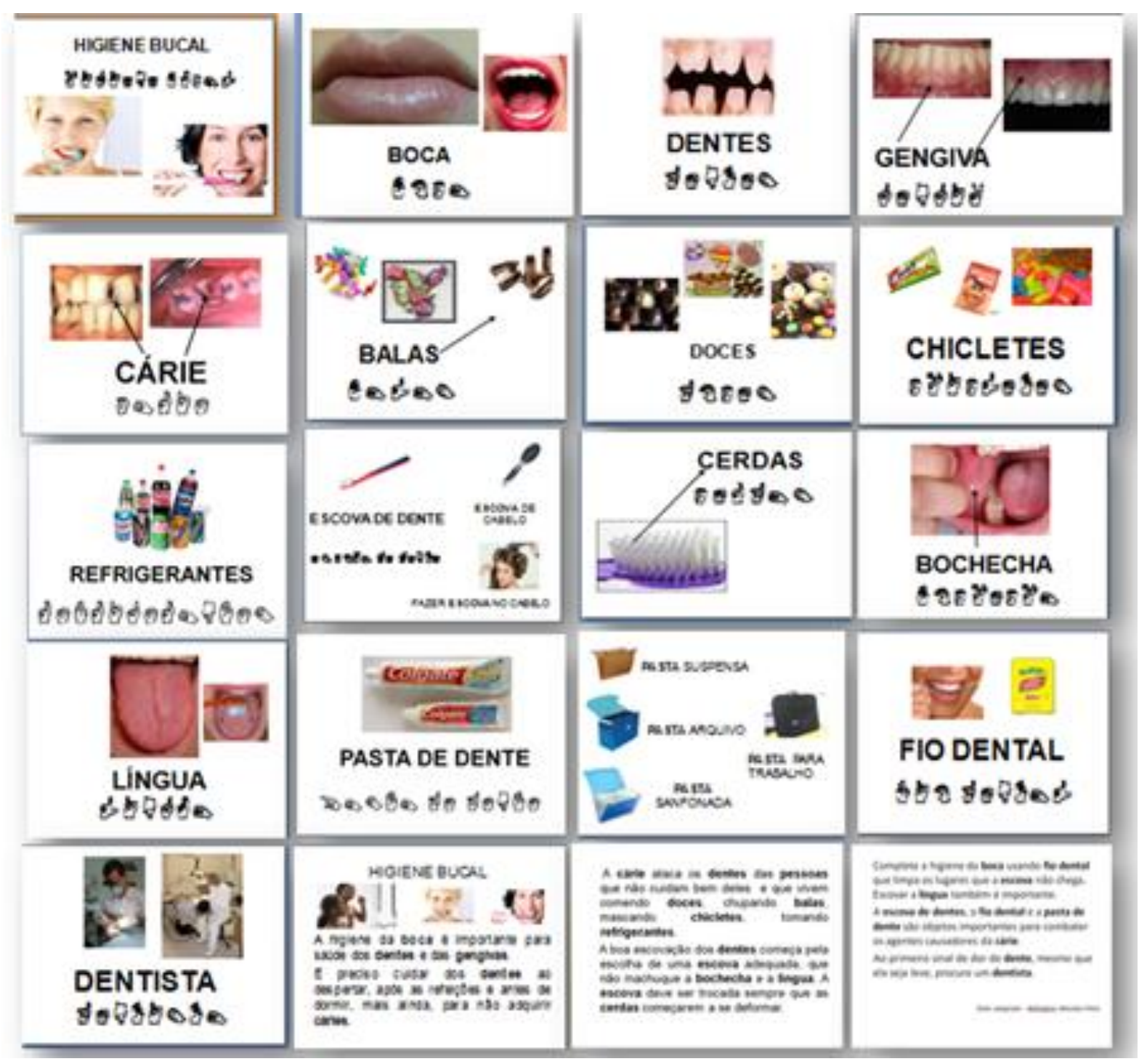

Fonte: Dados da Pesquisa. 


\section{DOI: $10.5902 / 1984686 \times 27435$}

Observando as filmagens, salienta-se que 0 uso do recurso didático imagético adequado com ênfase na experiência visual, facilitou toda a dinâmica das aulas, tornando muito mais fácil a explicação do conteúdo, estimulando a constituição do conhecimento de forma mais lúdica, atendendo a especificidade do sujeito surdo que utiliza o canal visual para interagir com o mundo. Sendo assim o acesso aos recursos tecnológicos precisam ser disponibilizados a contento.

Este artigo corrobora com o pensamento da autora Reily (2003) quando diz que o ensino do surdo se beneficia com a utilização de imagens visuais, uma vez que contribui com a elaboração de conceitos e ajuda no alargamento do pensamento conceitual, pois a imagem perpassa pelos diversos palcos do saber, favorece a transmissão do conhecimento e desenvolve o raciocínio.

Então, qual seria o caminho para a formação de professores de surdos? Segundo Sá (2011) um dos caminhos seria o de oportunizar aos professores o conhecimento da cultura surda e todas as suas especificidades.

O objetivo deve ser o de dar a todo futuro professor o conhecimento de
que existe uma minoria surda que é usuária de uma língua natural, e
que a ela tem direito. Os professores em formação devem ser
tranquilizados de que não se está esperando que eles, pela
obrigatoriedade legal de receber toda e qualquer criança em sua sala
de aula, seja obrigado a educar a criança surda utilizando a língua de
sinais, visto que, nem que fosse possível aprender a Libras em apenas
uma disciplina obrigatória de sua graduação, jamais seria possível
"falar" duas línguas ao mesmo tempo (SÁ, 2011, p. 43).

Portanto, o exercício da práxis docente com surdos requer dos docentes uma aproximação do mundo surdo através do conhecimento de sua cultura, tendo em vista a complexidade em que estes sujeitos são constituídos. Conhecer sua diferença cultural exige deslocar-se para o encontro do mundo espaço-visual e linguístico.

\section{Considerações finais}

Esta investigação confirmou dados anteriores sobre a importância da utilização da imagem visual aliado ao bilinguismo para a educação do surdo. As imagens e atividades selecionadas considerando a idade e nível de conhecimento do educando surdo possibilitou ricas interações, possibilitando um desenvolvimento mais sadio e harmonioso, oferecendo uma forma visual de acessibilidade ao conhecimento. 


\section{DOI: $10.5902 / 1984686 \times 27435$}

O presente estudo indicou a possibilidade de se pensar em recursos facilitadores da aprendizagem do surdo. O objetivo foi analisar o lugar que o recurso pedagógico visual imagético ocupa na práxis pedagógica dos docentes, com enfoque na educação bilíngue de educandos surdos do Ensino Fundamental I de uma escola em Salvador-BA.

Cabe à escola criar mecanismos internos para possibilitar um desempenho mais eficiente dos docentes como, por exemplo, a troca de experiências partilhadas de saberes, pois consolidam espaços de formação mútua, nos quais cada um é chamado a desempenhar, simultaneamente, o papel de formador e de formando, convertendo esses momentos em um programa de formação continuada e sistemática.

Diante disso, o estudo aponta para a necessidade de adequação do material didáticopedagógico em relação às necessidades específicas da pessoa surda em seu processo de aprendizagem. Deste modo, proporciona uma fluidez nos diálogos, favorecendo uma interação mais eficaz na sala de aula, tanto entre os sujeitos, como também em relação aos textos. São inúmeros os recursos didáticos que podem ser utilizados na educação de surdos. O aspecto que faz a diferença é, sem dúvida, a criatividade do docente.

\section{Referências}

ALMEIDA, M. E. B.; PRADO, M. E. B.B. P. Redesenhando estratégias na própria ação: formação do professor a distância em ambiente digital. In: José Armando Valente, Maria Elizabeth B. de Almeida, Maria Elisabette B. Prado. Educação a distância via Internet. Formação de professores. São Paulo: Avercamp, 2003.

BUZAR, E. A. S. A Singularidade visuo-espacial do sujeito surdo: implicações educacionais. Dissertação de mestrado. Brasília: Faculdade de Educação da UnB, 2009.

BRASIL. Decreto n 5.626 de 22 de dezembro de 2005. Regulamenta a Lei nำ 10.436, de 24 de abril de 2002, que dispõe sobre a Língua Brasileira de Sinais - Libras e o artigo 18 da Lei no 10.098, de 19 de dezembro de 2000. Brasília, 2005. Disponível em: http://www.planalto.gov.br/ccivil_03/_ato2004-2006/2005/decreto/d5626.htm. Acesso em: 10 de janeiro de 2016.

CAMPELLO, A. R. S. Pedagogia visual: sinal na educação dos surdos. In: QUADROS, R. M. de.; PELIN, G. (orgs). Estudos Surdos II. Petrópolis: Arara Azul. p. 100-131, 2007. 
DOI: $10.5902 / 1984686 \times 27435$

GOLDFELD, Márcia. A criança surda: linguagem e cognição numa perspectiva sóciointeracionista. São Paulo: Plexus, 2002. 173 p

KELMAN, C. A. Significação e aprendizagem do aluno surdo. In MARTÍNEZ, A. M.; TACCA, M. C. V. R. (Orgs.) Possibilidades de aprendizagem: ações pedagógicas para alunos com dificuldade e deficiência. Campinas: Unix, 2011

LACERDA, C. B. F. de.; SANTOS, L. F.; CAETANO, J. F. Estratégias metodológicas para o ensino de alunos surdos. In: Língua brasileira de sinais: libras uma introdução. São Paulo: UAB-UFSCar, p. 103-118, 2011.

LARROSA, J. Pedagogia profana: danças, piruetas e mascaradas. Trad. Alfredo VeigaNeto. Belo Horizonte: Autêntica, 2003.

MINAYO, M. C. S. (Org.). Pesquisa social: teoria, método e criatividade. Petrópolis: Vozes, 2007.

OLIVEIRA, P. A. de. Eros e Thanatos: um estudo em representações sociais da formação do professor sobre sua práxis com surdos. Salvador: Edufba, 2009.

PERLIN, Gladis; MIRANDA, Wilson. A performatividade em educação de surdos. Cap. IV, p. 101-117. In: SÁ, Nídia Regina Limeira de (Org.). Surdos: qual escola? Manaus: Editora Valer e Edua, 2011. 302p. ISBN 978-85-7401-558-3. Disponível em: http:// www.socepel.com.br/_arquivos/LIVRO_SOBRE_SURDOS/Surdos_Qual_Escolar. pdf>. Acesso em 23/03/2018.

REILY, L. H. As imagens: o lúdico e o absurdo no ensino de arte para pré-escolares surdos. In.: SILVA, I. R.; KAUCHAKJE, S.; GESUELI, Z. (Orgs.). Cidadania, surdez e linguagem: desafios e realidades. Cap. IX (pp.161-192). São Paulo: Plexus, 2003.

SÁ, N. L. Educação de surdos: a caminho do bilinguismo. Rio de Janeiro, Editora da Universidade Federal Fuminense, 1999.

SÁNCHEZ, C. La Educación de los sordos em un modelo bilíngue. Mérida: lakonia, 1991.

SILVA, M. da P. M. A construção de sentido na escrita do aluno surdo. São Paulo: Plexus; 2001. 
DOI: $10.5902 / 1984686 \times 27435$

SIMÕES, E. da S.; ZAVA, D. H.; SILVA, G. C. F. da. \& KELMAN, C. A. Menos do mesmo: a pedagogia visual na construção da L2. VII Encontro da Associação Brasileira de Pesquisadores em Educação Especial. Londrina, 2011. p. 3608-3616.

SKLIAR, C. (Org). Educação e Exclusão: abordagem sócio-antropológica em Educação Especial. Porto Alegre: Mediação, 1997.

SKLIAR, C. A surdez: um olhar sobre as diferenças. 6. ed. Porto Alegre: Mediação, 2013. SKLIAR, C. B. Um olhar sobre nosso olhar acerca da surdez e as deferências. In: SKLIAR. Carlos. B. (Org). A Surdez: um olhar sobre as diferenças. Porto Alegre: Mediação, 1998.

SKLIAR, C. Uma perspectiva sócio-histórica sobre a psicologia e a educação dos surdos. In: SKLIAR, C. (Org.). Educação e exclusão: abor- dagens socioantropológicas em educação especial. Porto Alegre: Me- diação, 1997. p. 105-153. (Cadernos de autoria, 2)

STROBEL, K. As imagens do outro sobre a cultura surda. 2 ed. Florianópolis: Ed. UFSC, 2009 .

STROBEL, K. As imagens do outro sobre a cultura surda. Florianópolis: Ed da UFSC, 2008. 118 p.

THIOLLENT, M. Metodologia da pesquisa-ação. 15. ed. São Paulo: Cortez, 2007 VYGOTSKY, Lev S. Pensamento e Linguagem. São Paulo: Martins Fontes, 1999.

\section{Agradecimento}

À Iraudice Madalena da Silva Nunes por fornecer dados para elaboração de algumas das análises deste artigo.

\section{Correspondência}

Patrícia da Hora Correia - Av. Reitor Miguel Calmon, Sala Gec, Vale do Canela. CEP: 40110-100. Salvador, Bahia, Brasil.

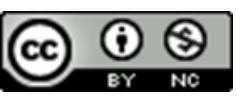

This work is licensed under a Creative Commons Attribution-NonCommercial 4.0 International (CC BY-NC 4.0) 